\title{
Pharmacokinetic Study of Safrole and Methyl Eugenol after Oral Administration of the Essential Oil Extracts of Asarum in Rats by GC-MS
}

\author{
Yuqi Fan $\mathbb{D},{ }^{1,2}$ Dongyue Yang, ${ }^{2}$ Xuhua Huang, ${ }^{2}$ Guangzhe Yao, ${ }^{2}$ Wei Wang, ${ }^{2}$ \\ Mengyuan Gao, ${ }^{2}$ Xiaohua Jia, ${ }^{2}$ Huizi Ouyang $\mathbb{D}^{1,2}$ Yanxu Chang, ${ }^{2}$ and Jun He $\mathbb{D}^{2}$ \\ ${ }^{1}$ First Teaching Hospital of Tianjin University of Traditional Chinese Medicine, 300193 Tianjin, China \\ ${ }^{2}$ State Key Laboratory of Component-Based Chinese Medicine, Tianjin University of Traditional Chinese Medicine, \\ Tianjin 301617, China
}

Correspondence should be addressed to Huizi Ouyang; huihui851025@163.com and Jun He; hejun673@163.com

Received 27 October 2020; Revised 17 January 2021; Accepted 11 March 2021; Published 20 March 2021

Academic Editor: Sun Jin Hur

Copyright (C) 2021 Yuqi Fan et al. This is an open access article distributed under the Creative Commons Attribution License, which permits unrestricted use, distribution, and reproduction in any medium, provided the original work is properly cited.

\begin{abstract}
Asarum is a traditional medicine and has been widely used as remedies for inflammatory diseases, toothache, headache, local anesthesia, and aphthous stomatitis in China, Japan, and Korea. Our previous research found that safrole and methyl eugenol were vital compounds that contribute to distinguish the different species and raw Asarum and its processed products apart. The pharmacokinetics of safrole and methyl eugenol after oral administration of Asarum extract has not been reported yet. In this study, a rapid and simple gas chromatography-mass spectroscopy (GC-MS) method that has a complete run time of only $4.5 \mathrm{~min}$ was developed and validated for the simultaneous determination and pharmacokinetic study of safrole and methyl eugenol in rat plasma after administration of Asarum extracts. The chromatographic separation was realized on a DB-17 column $(30 \mathrm{~m} \times 0.25 \mathrm{~mm} \times 0.25 \mu \mathrm{m})$. And detection was carried out under selected ion monitoring (SIM) mode. Plasma samples were pretreated by $n$-hexane. The pharmacokinetic parameters provided by this study will be beneficial for further developments and clinical applications of Asarum.
\end{abstract}

\section{Introduction}

Asarum, with the Chinese name Xixin, is a perennial plant that is widely distributed in China, Japan, and Korea. It originates in the roots and rhizomes of Asarum sieboldii Miq., Asarum sieboldii Miq. var. seoulense Nakai, and Asarum heterotropoides Fr. Schmidt var. mandshuricum (Maxim.) Kitag [1]. Asarum is a traditional medicine and has been widely used as remedies for inflammatory diseases, toothache, headache, local anesthesia, and aphthous stomatitis in many countries [2]. Phytochemical studies on this herb showed that the components of Asarum included volatile oil, flavonoids, aristolochic acids, and furofurans-type lignan [3, 4]. Among these components, volatile oils are not only the major bioactive compounds but also the toxic compounds of Asarum. It has attracted wide attention from researchers because of its high content and strong activities. Modern pharmacological studies have demonstrated that various volatile oil ingredients in Asarum have a lot of activities such as antibacterial, treatment of allergic rhinitis, antinociceptive, anti-inflammatory, and antiallergic [5-9]. On the other hand, toxicological researchers found that the volatile oil ingredients in Asarum have strong phytotoxic activity and it was toxic to D. farinae adults $[10,11]$.

Prior to the use of traditional Chinese medicine, most toxic raw herbs must be subjected to chemical and/or physical pretreatment processes after harvest for preservation, detoxification, or efficacy enhancement [12]. After processing, the chemical components of raw herbs and processed products often change, and these changed components might be the material basis of the herb increasing efficiency or reducing toxicity [13]. Our previous research used PLS-DA analysis to distinguish and predict Asarum samples of different species and its processed products, and the results 
indicated that the safrole and methyl eugenol were identified as key compounds that can be beneficial to differentiate the different species apart. Apart from that, both of these two volatile oils were notable index constituents to differentiate raw Asarum and its processed products [14].

The methyl eugenol and safrole are common volatile oil compounds found in many plants and had been widely used as a flavoring agent in people's daily life $[15,16]$. But both of these two compounds were found to be carcinogenic and have been set as a group $2 \mathrm{~B}$ carcinogen by International Agency for Research on Cancer (IARC) [17, 18]. Some researchers have studied the elimination of methyl eugenol from serum after administration of the standards of methyl eugenol [19]. However, to the best of our knowledge, there is still a lack of information on the pharmacokinetics study of methyl eugenol and safrole simultaneously in vivo after oral administration of Asarum essential oil extract.

Many studies have shown that these two compounds might be the main active ingredients of Asarum for various medicinal effects such as acaricidal activity and antifungal effect $[20,21]$. Therefore, understanding the pharmacokinetic activities of these two components in vivo after administration of Asarum extracts is of great significance for finding out how Asarum exerts its pharmacological or toxicological effects in vivo.

Previously developed methods for the identification and quantitation of the bioactive components of Asarum include the headspace GC-MS and the UHPLC-Q-TOF/MS [22, 23]. The focus of previous researches was on the components of Asarum in vitro. GC/MS in the selected ion-monitoring mode (SIM) method was always used for identification and quantitation in recent years, and it is more specific compared to scan mode [24-26]. In this current study, a simple and sensitive GC-MS method performed under SIM mode was established for simultaneously quantifying safrole and methyl eugenol in rat plasma. This method has a complete run time of only $4.5 \mathrm{~min}$, and it was first used for the pharmacokinetic analysis of safrole and methyl eugenol in rat plasma simultaneously after administration of Asarum essential oil extracts.

\section{Material and Methods}

2.1. Materials. Safrole, methyl eugenol, and menthone (IS) were obtained from Desite Biotech Co., Ltd. (Chengdu, China). The chemical structures of them are displayed in Figure 1. Asarum was purchased from Liaoning province in China. N-Hexane was purchased from Kangkede Technology Co., Ltd (Tianjin, China). A Mili-Q water purification system (Millipore, Milford, MA, USA) was used for preparing the ultrapure water.

2.2. GC-MS Analysis. The GC-MS system (Shimadzu GCMS QP-2010 Ultrasystem) was coupled with an AOC-20i autosampler. The column used was a DB-17 capillary column (30 $\mathrm{m} \times 0.25 \mathrm{~mm} \times 0.25 \mu \mathrm{m}$ film thickness). $99.99 \%$ high purity Helium was used as the carrier gas with a flow rate of $1.3 \mathrm{~mL} / \mathrm{min}$. The column temperature was programmed as follows: initial temperature $90^{\circ} \mathrm{C}, 20^{\circ} \mathrm{C} / \mathrm{min}$ to $106^{\circ} \mathrm{C}$, $30^{\circ} \mathrm{C} / \mathrm{min}$ to $136^{\circ} \mathrm{C}, 40^{\circ} \mathrm{C} / \mathrm{min}$ to $210^{\circ} \mathrm{C}$, and finally $5.5^{\circ} \mathrm{C} / \mathrm{min}$ to $214^{\circ} \mathrm{C}$. The injection volume was $1 \mu \mathrm{L}$, and the injection temperature was $250^{\circ} \mathrm{C}$.

The MS data were acquired in the electron-impact mode, and the SIM mode was used for quantification. The three characteristic ions of safrole were 162.0, 131.0, and 104.0 and that of methyl eugenols were 178.0, 163.0, and 147.0 (ions in bold fonts were used for the quantification). The obtained mass spectrums are shown in Figure 2. The transfer line temperature was set at $250^{\circ} \mathrm{C}$, and the ionization source temperature was set at $230^{\circ} \mathrm{C}$. The total run time was $4.5 \mathrm{~min}$ with a solvent delay of $3 \mathrm{~min}$.

2.3. Asarum Extracts Preparation. The Asarum powder sample was accurately weighed $50.0 \mathrm{~g}$ and extracted by an essential oil extractor for $6 \mathrm{~h}$ at 100 volt. After cooling to room temperature, the extracted essential oils were collected, and anhydrous sodium sulfate was then used to dehydrate the volatile oil. The obtained essential oil was stored at $4^{\circ} \mathrm{C}$ until analysis. The contents of methyl eugenol and safrole in the extract were 38.3 and $13.2 \mathrm{mg} / \mathrm{g}$, respectively.

2.4. Preparation of Standard and Calibration Curves. Safrole, methyl eugenol, and menthone (internal standard, IS) were separately weighed $10 \mathrm{mg}$ and dissolved with an appropriate volume of $n$-hexane to a concentration of $140 \mu \mathrm{g} / \mathrm{mL}$, $100 \mu \mathrm{g} / \mathrm{mL}$, and $50 \mu \mathrm{g} / \mathrm{mL}$, respectively, as standard stock solutions. The calibration solutions were prepared by adding appropriate volumes of mixture working solution and $10 \mu \mathrm{L}$ of IS into $100 \mu \mathrm{L}$ blank rat plasma, resulting in concentrations: 70, 140, 350, 700, 1400, 3500, 7000, and $14000 \mathrm{ng} / \mathrm{mL}$ for safrole and 50, 100, 250, 500, 1000, 2500, 5000, and $10000 \mathrm{ng} / \mathrm{mL}$ for methyl eugenol. Quality control (QC) samples at three levels (low, medium, and high concentration) were prepared in the same manner. All the samples were kept at $4^{\circ} \mathrm{C}$ before use.

2.5. Preparation of Plasma Sample. $100 \mu \mathrm{L}$ plasma sample was incorporated with $10 \mu \mathrm{L}$ n-hexane and $10 \mu \mathrm{L}$ of IS $(5 \mu \mathrm{g} / \mathrm{mL})$ and vortexed for 30 seconds. $130 \mu \mathrm{L} n$-hexane was then added to the sample and vortex-mixed for $5 \mathrm{~min}$. The samples were centrifuged $\left(12,000 \times \mathrm{g}, 10 \mathrm{~min}, 4^{\circ} \mathrm{C}\right)$, and $10 \mu \mathrm{L}$ supernatant was injected for GC-MS analysis.

\subsection{Method Validation}

2.6.1. Specificity. The specificity was measured by comparing the chromatograms of blank plasma, blank plasma spiked with analytes and IS, and plasma samples obtained after oral administration of Asarum essential oil extracts.

2.6.2. Linearity and Sensitivity. To assess the linearity, we constructed a calibration curve by analyzing the spiked calibration samples. The calibration curve was measured by $1 / \mathrm{x}$ weighted regression, and it was constructed based on peak area ratios of analytes against the internal standards. The lower limit of detection (LLOD) was defined as a concentration that $\mathrm{S} / \mathrm{N}$ ratio of 3 , and the lower limit of quantification (LLOQ) was determined as the concentration which provided a signal-to-noise $(\mathrm{S} / \mathrm{N})$ ratio of 10 . The acceptable 
<smiles>C=CCc1ccc2c(c1)OCO2</smiles><smiles>C=CCc1ccc(OC)c(OC)c1</smiles>

(a)

(b)

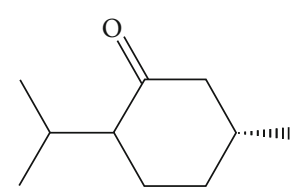

(c)

FIGURE 1: The chemical structures of (a) safrole, (b) methyl eugenol, and (c) IS.

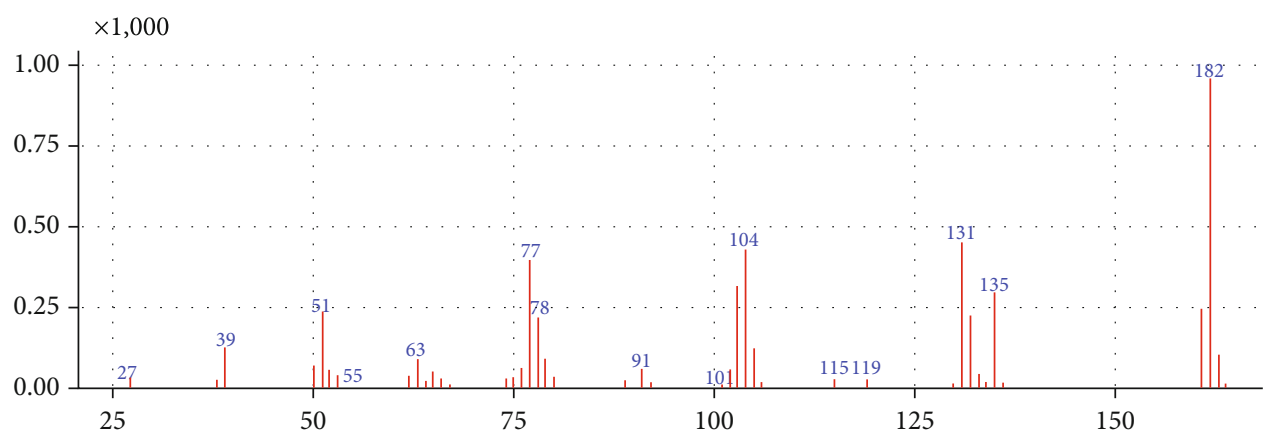

(a)

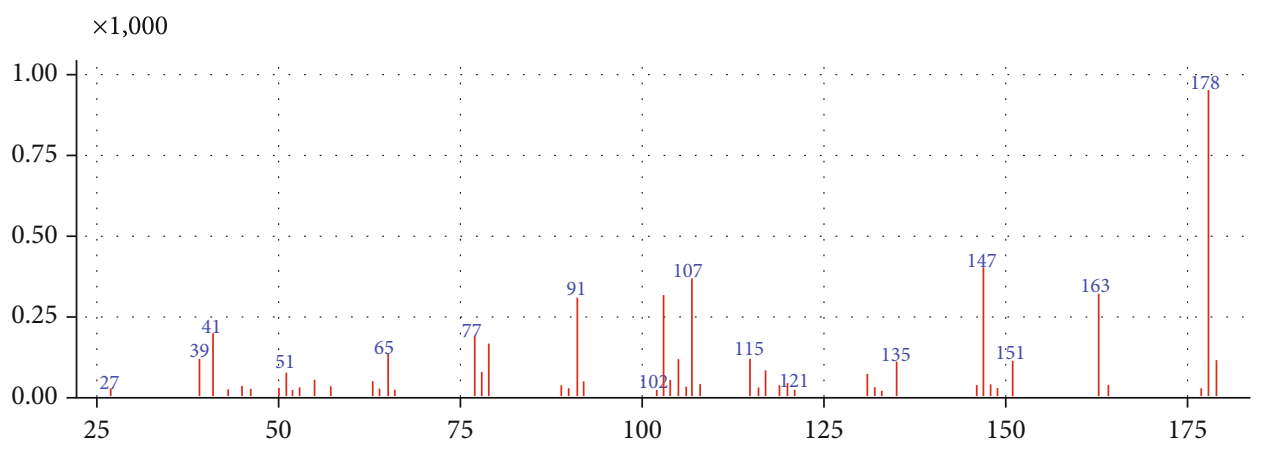

(b)

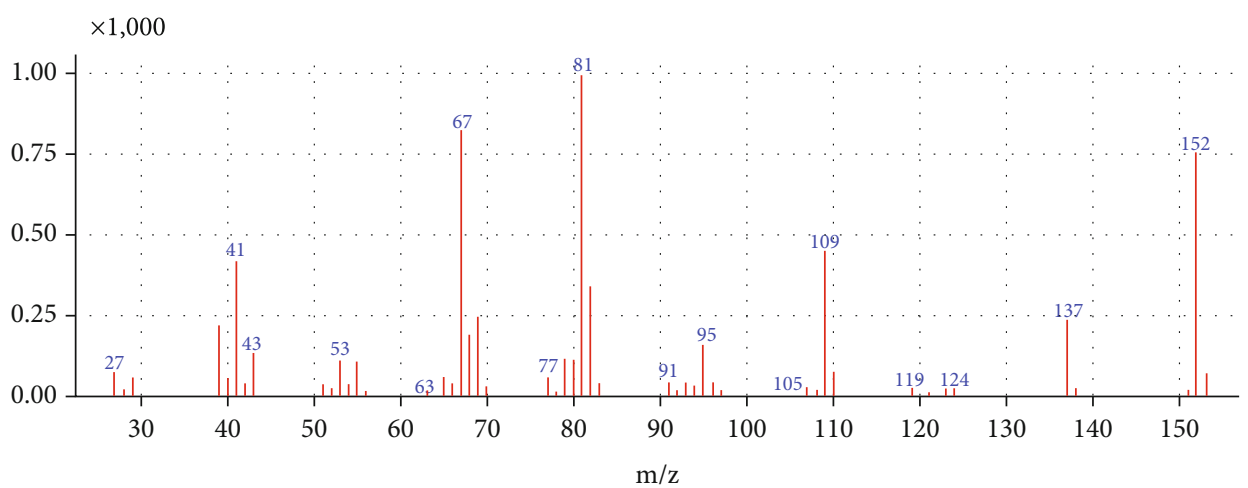

(c)

FIGURe 2: Mass spectrums of (a) safrole, (b) methyl eugenol, and (c) IS. 
accuracy (RE) was within $\pm 20 \%$, and the relative standard deviation (RSD) was below $20 \%$.

2.6.3. Precision and Accuracy. The intra- and interday accuracy and precision each day and three consecutive days were evaluated by measuring quality control (QC) samples at three different concentration levels $(120,1200$, and $12000 \mathrm{ng} / \mathrm{mL}$ for safrole; 80,800 , and $8000 \mathrm{ng} / \mathrm{mL}$ for methyl eugenol). The relative error (RE, \%) and the relative standard deviation (RSD, \%) were used for expressing the intra- and interday accuracy and precisions, respectively.

2.6.4. Matrix Effect and Extraction Recovery. The low, medium, and high concentration samples in six replicates were used to analyze the extraction recovery. The extraction recovery was calculated through comparing the peak areas of QC samples with those in postextracted spiked samples. The matrix effects were studied by comparing the peak areas of QC samples spiked postextraction to those acquired from nonextracted samples.

2.6.5. Stability. The stability was evaluated under different condition with variable time and temperature including long-term stability (storing the QC samples at $-80^{\circ} \mathrm{C}$ for 7 days), short-term stability (storing the QC samples at room temperature for $4 \mathrm{~h}$ ), freeze/thaw stability (three freeze $\left(-20^{\circ} \mathrm{C}\right)$ thaw cycles), and auto-sampler stability (incubating the spiked samples for $12 \mathrm{~h}$ in auto-sampler).

2.7. Application. All animal protocols were approved by the Laboratory Animal Ethics Committee of Tianjin University Traditional Chinese Medicine (TCM-LAEC20190059). Six male Sprague-Dawley rats (body weight $240 \pm 10 \mathrm{~g}$ ) were fasted for $12 \mathrm{~h}$ prior to the study, with free access to water. The Asarum extracts were administered to rats orally at a dose of $20 \mathrm{~g} / \mathrm{kg}$. $0.5 \%$ CMC-Na aqueous solution was used to dissolve the Asarum extracts to a concentration of $2 \mathrm{~g} / \mathrm{mL}$ suspension and stored at $4^{\circ} \mathrm{C}$. Approximately $220 \mu \mathrm{L}$ blood samples were collected from the suborbital vein into centrifuge tubes at $0,0.08,0.17,0.5,1,2,4,6,8,10,12,24$, 36,48 , and $60 \mathrm{~h}$ postadministration in rats. The plasma was separated by centrifugation at $4000 \times g$ for 10 min immediately and frozen at $-80^{\circ} \mathrm{C}$ until the time of analysis. The main program pharmacokinetic parameters were processed by Drug and Statistics 3.0 (Medical College of Wannan, China).

\section{Results and Discussion}

3.1. Optimization of Pretreatment Procedure. For the pretreatment of plasma samples, two different pretreatment methods (liquid-liquid extraction and protein precipitation methods) were utilized in this study. Results showed that liquid-liquid extraction (LLE) with $n$-hexane and ethyl acetate both could obtain reproducible extraction and good recovery for the analytes, while the protein precipitation extraction with methanol and acetonitrile was found to contain endogenous interference. However, considering that the plasma endogenous substances interfere with the determination of the analytes after the ethyl acetate treatment, $n$-hexane was chosen to be the extraction solvent for this experiment.
3.2. Optimization of Internal Standard Compounds. In order to ensure the accuracy of the experimental determination, the relative molecular mass, boiling point, and retention time of the internal standard compound and the analytes should be similar and can be separated well. The experiment investigated the influence of menthone and m-xylene as internal standard compounds on the analysis samples. The results demonstrated that the menthone's structure was similar to the analytes, and it can be separated well within $4.5 \mathrm{~min}$, which satisfied the measurement requirements. Therefore, menthone was used in the experiment as the internal standard.

\subsection{Method Validation}

3.3.1. Specificity. The SIM chromatograms of blank plasma, plasma spiked with safrole, methyl eugenol and IS, and plasma sample obtained after oral administration Asarum extracts were shown in Figure 3. The retention time of safrole, methyl eugenol, and menthone were $3.678,4.132$, and $3.385 \mathrm{~min}$, respectively. There were no interference peaks at the retention time of analytes and IS.

3.3.2. Linearity and Sensitivity. The calibration curves, the linearity ranges, LLOQ, and LLOD values for the analytes are summarized in Table 1. The plasma calibration curves exhibited good linear relationship within the range of 70 $14000 \mathrm{ng} / \mathrm{mL}$ for safrole and $50-10000 \mathrm{ng} / \mathrm{mL}$ for methyl eugenol. The correlation coefficients of the two compounds were both 0.999 .

3.3.3. Precision and Accuracy. The data of the intra- and interday precision and accuracy are summed up in Table 2. The results showed that at each QC level of two compounds, the RSD values were below $9.8 \%$ for intra- and interday precisions, and the RE values of average accuracy were from $-7.9 \%$ to $11.4 \%$.

3.3.4. Matrix Effect and Extraction Recovery. The mean matrix effect ratio for all analytes and IS ranged from 80.6 $\pm 2.2 \%$ to $104.8 \pm 7.4 \%$, and the mean recovery rates of safrole and methyl eugenol ranged from $84.6 \pm 5.6 \%$ to $97.6 \pm$ $5.5 \%$ (Table 3 ). The results demonstrated that the influence from the plasma matrix was negligible.

3.3.5. Stability. The stability of analytes in rat plasma under different conditions is summed up in Table 4, which shows that the RSD value of the replicate QC samples was less than 9.9\%. Safrole and methyl eugenol in plasma samples were found to be stable under all conditions studied.

3.4. Pharmacokinetic Studies. The validated method in this paper was successfully applied to the pharmacokinetic study of safrole and methyl eugenol in rat plasma after oral administration of the essential oil extracts of Asarum. Figure 4 shows the mean plasma concentration-time profile of the bioactive ingredients and the calculated main pharmacokinetic parameters is presented in Table 5 .

The main pharmacokinetic parameters are listed in Table 5 including the maximum plasma concentration $C_{\max }$ 


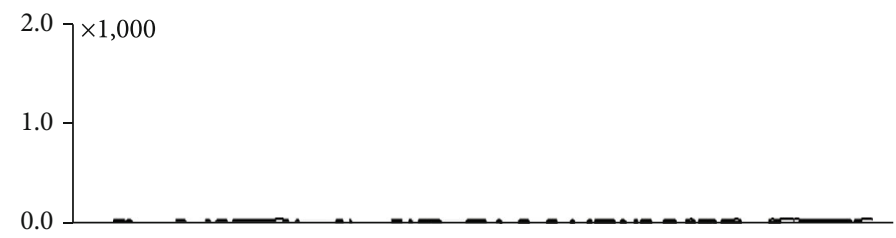

(a)

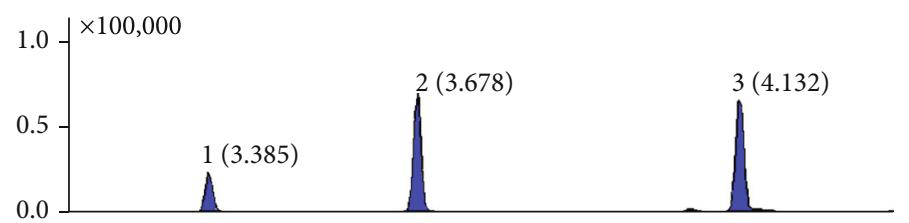

(b)

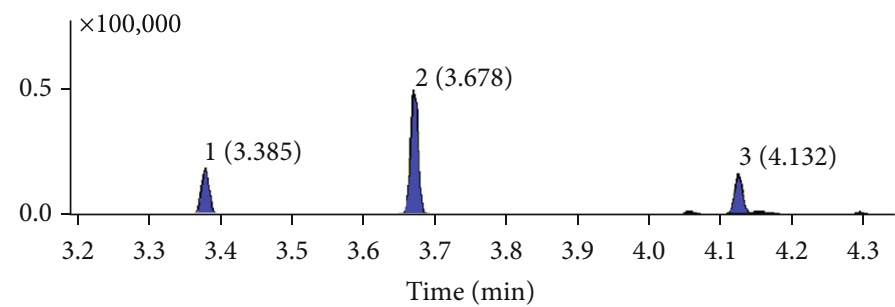

(c)

FIGURE 3: The typical chromatograms of (1) IS, (2) safrole, and (3) methyl eugenol: (a) blank plasma, (b) blank plasma spiked with analytes and IS, and (C) plasma sample.

TABLE 1: Calibration curves, correlation coefficients, linear ranges LLOD, and LLOQ of the 2 analytes.

\begin{tabular}{lccccc}
\hline Compounds & Calibration curves & Correlation coefficients $\left(r^{2}\right)$ & Linear range $(\mathrm{ng} / \mathrm{mL})$ & LLOD $(\mathrm{ng} / \mathrm{mL})$ & LLOQ $(\mathrm{ng} / \mathrm{mL})$ \\
\hline Safrole & $Y=1.13 e^{-003} X-3.34 e-002$ & 0.999 & $70-14000$ & 10.5 & 35 \\
Methyl eugenol & $Y=1.59 e^{-003} X-4.52 e-002$ & 0.999 & $50-10000$ & 7.5 & 25 \\
\hline
\end{tabular}

TABle 2: Precision and accuracy of 2 analytes in rat plasma $(n=6)$.

\begin{tabular}{lccccccc}
\hline Compounds & $\begin{array}{c}\text { Spiked } \\
\text { concentration } \\
(\mathrm{ng} / \mathrm{mL})\end{array}$ & $\begin{array}{c}\text { Measured } \\
\text { concentration } \\
(\mathrm{ng} / \mathrm{mL})\end{array}$ & $\begin{array}{c}\text { Intraday } \\
\text { Accuracy } \\
(\mathrm{RE}, \%)\end{array}$ & $\begin{array}{c}\text { Precision } \\
(\mathrm{RSD}, \%)\end{array}$ & $\begin{array}{c}\text { Measured } \\
\text { concentration } \\
(\mathrm{ng} / \mathrm{mL})\end{array}$ & $\begin{array}{c}\text { Accuracy } \\
(\mathrm{RE}, \%)\end{array}$ & $\begin{array}{c}\text { Precision } \\
(\mathrm{RSD}, \%)\end{array}$ \\
\hline \multirow{3}{*}{ Safrole } & 120 & $131.1 \pm 9.9$ & 9.2 & 7.6 & $133.7 \pm 8.2$ & 11.4 & 6.1 \\
& 1200 & $1302.3 \pm 14.2$ & 8.5 & 1.1 & $1329.3 \pm 28.7$ & 10.8 & 2.2 \\
Methyl & 12000 & $12658.9 \pm 83.5$ & 5.5 & 0.7 & $12769.7 \pm 185.2$ & 6.4 & 1.5 \\
eugenol & 80 & $86.6 \pm 8.5$ & 8.2 & 9.8 & $75.6 \pm 6.0$ & -5.5 & 8.0 \\
& 800 & $746.0 \pm 13.8$ & -6.8 & 1.9 & $742.4 \pm 14.4$ & -7.2 & 1.9 \\
\hline
\end{tabular}

and time to reach $C_{\max }$ of each compound $\left(T_{\max }\right)$. The $T_{1 / 2}$ was the elimination half-life, and it reflects the elimination rate of the drug in the body. The area under the plasma concentration-time curve $\mathrm{AUC}_{(0-t)}$ was calculated using the trapezoidal rule and extrapolated to infinity for $\mathrm{AUC}_{(0-\infty)}$. The mean residence time (MRT) of safrole and methyl eugenol was also investigated.

As seen from the results, the $C_{\max }$ of safrole and methyl eugenol was $1979.5 \pm 267.1$ and $823.0 \pm 123.8$, separately, indicating that the blood concentrations of the two com- pounds were high and that their absorptions were complete. The $T_{\max }$ of safrole and methyl eugenol was $13.00 \pm 1.10 \mathrm{~h}$ and $6.67 \pm 2.07 \mathrm{~h}$, respectively, showing that the absorption of methyl eugenol was faster than safrole. The $T_{1 / 2}$ of safrole and methyl eugenol was $2.44 \pm 2.72$ and $3.67 \pm 1.60 \mathrm{~h}$, respectively. The $\mathrm{AUC}_{(0-t)}$ and the $\mathrm{AUC}_{(0-\infty)}$ of both two compounds were close by, indicating that the monitoring time of this study was appropriate. The result of mean residence time was consistent with the concentration-time profile that the long mean residence time of safrole 
TABle 3: Matrix effect and extraction recovery of 2 analytes $(n=6)$.

\begin{tabular}{|c|c|c|c|c|c|}
\hline Compounds & Spiked concentration $(\mathrm{ng} / \mathrm{mL})$ & Extraction recovery $(\%)$ & RSD (\%) & Matrix effect (\%) & RSD (\%) \\
\hline \multirow{3}{*}{ Safrole } & 120 & $91.8 \pm 2.6$ & 2.8 & $80.6 \pm 2.2$ & 2.7 \\
\hline & 1200 & $90.7 \pm 3.6$ & 4.0 & $90.9 \pm 7.6$ & 8.3 \\
\hline & 12000 & $84.6 \pm 5.6$ & 6.6 & $88.0 \pm 3.5$ & 3.9 \\
\hline \multirow{3}{*}{ Methyl eugenol } & 80 & $92.5 \pm 3.6$ & 3.9 & $88.6 \pm 3.5$ & 3.9 \\
\hline & 800 & $87.9 \pm 4.4$ & 5.0 & $97.6 \pm 5.7$ & 5.9 \\
\hline & 8000 & $97.6 \pm 5.5$ & 5.6 & $104.8 \pm 7.4$ & 7.1 \\
\hline
\end{tabular}

TABLE 4: Stability of 2 analytes in rat plasma $(n=6)$.

\begin{tabular}{|c|c|c|c|c|c|c|c|c|c|}
\hline \multirow[b]{2}{*}{ Compounds } & \multirow{2}{*}{$\begin{array}{c}\text { Spiked } \\
\text { concentration } \\
(\mathrm{ng} / \mathrm{mL})\end{array}$} & \multicolumn{2}{|c|}{$\begin{array}{l}\text { Room temperature for } \\
4 \mathrm{~h}\end{array}$} & \multicolumn{2}{|c|}{ Three freeze-thaw cycles } & \multicolumn{2}{|c|}{ Auto-sampler for $12 \mathrm{~h}$} & \multicolumn{2}{|c|}{$-80^{\circ} \mathrm{C}$ for 7 days } \\
\hline & & $\begin{array}{c}\text { Measured } \\
\text { concentration } \\
(\mathrm{ng} / \mathrm{mL})\end{array}$ & $\begin{array}{l}\mathrm{RSD} \\
(\%)\end{array}$ & $\begin{array}{c}\text { Measured } \\
\text { concentration } \\
(\mathrm{ng} / \mathrm{mL})\end{array}$ & $\begin{array}{l}\text { RSD } \\
(\%)\end{array}$ & $\begin{array}{c}\text { Measured } \\
\text { concentration } \\
(\mathrm{ng} / \mathrm{mL})\end{array}$ & $\begin{array}{l}\text { RSD } \\
(\%)\end{array}$ & $\begin{array}{c}\text { Measured } \\
\text { concentration } \\
(\mathrm{ng} / \mathrm{mL})\end{array}$ & $\begin{array}{l}\text { RSD } \\
(\%)\end{array}$ \\
\hline \multirow{3}{*}{ Safrole } & 120 & $132.5 \pm 12.4$ & 9.3 & $137.0 \pm 10.6$ & 7.8 & $136.3 \pm 11.8$ & 8.7 & $135.1 \pm 11.0$ & 8.2 \\
\hline & 1200 & $1306.7 \pm 15.7$ & 1.2 & $1319.7 \pm 21.2$ & 1.6 & $1271.1 \pm 3.3$ & 0.3 & $1348.1 \pm 41.4$ & 3.1 \\
\hline & 12000 & $12751.7 \pm 38.6$ & 0.3 & $12526.3 \pm 331.5$ & 2.7 & $12065.2 \pm 210.7$ & 1.8 & $12741.7 \pm 103.1$ & 0.8 \\
\hline \multirow{3}{*}{$\begin{array}{l}\text { Methyl } \\
\text { eugenol }\end{array}$} & 80 & $89.6 \pm 8.8$ & 9.9 & $78.5 \pm 6.5$ & 8.2 & $73.9 \pm 6.1$ & 8.2 & $81.0 \pm 5.2$ & 6.5 \\
\hline & 800 & $751.7 \pm 7.8$ & 1.0 & $708.5 \pm 16.2$ & 2.3 & $727.7 \pm 6.0$ & 0.8 & $749.8 \pm 40.7$ & 5.4 \\
\hline & 8000 & $7418.6 \pm 62.9$ & 0.9 & $7287.0 \pm 522.7$ & 7.2 & $7100.8 \pm 230.4$ & 3.2 & $7367.9 \pm 638.7$ & 8.7 \\
\hline
\end{tabular}

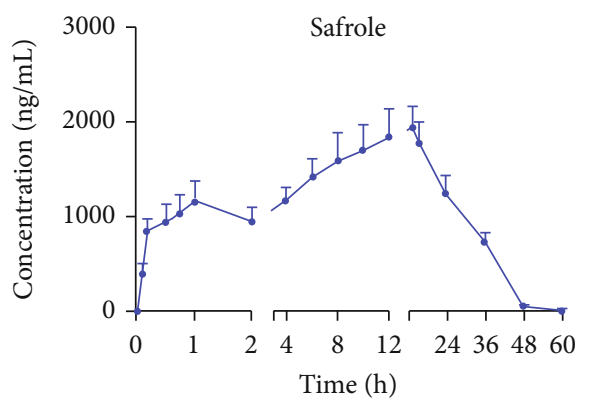

(a)

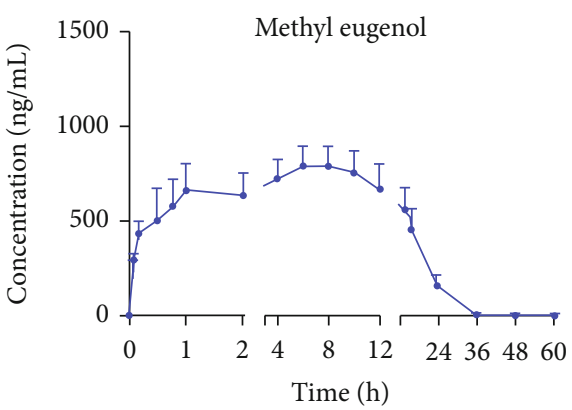

(b)

FIgURE 4: Mean plasma concentration-time curves of safrole and methyl eugenol after oral administration of Asarum extract (mean \pm SD, $n=6)$.

TABle 5: Main pharmacokinetic parameters of 2 analytes in rat plasma $(n=6$, mean $\pm \mathrm{SD})$.

\begin{tabular}{lcc}
\hline Parameters & Safrole & Methyl eugenol \\
\hline$C_{\text {max }}(\mathrm{ng} / \mathrm{mL})$ & $1979.5 \pm 267.1$ & $823.0 \pm 123.8$ \\
$T_{\max }(\mathrm{h})$ & $13.00 \pm 1.10$ & $6.67 \pm 2.07$ \\
$T_{1 / 2}(\mathrm{~h})$ & $2.44 \pm 2.72$ & $3.67 \pm 1.60$ \\
$\mathrm{AUC}_{(0-t)}(\mathrm{h} \mathrm{ng} / \mathrm{mL})$ & $52974.6 \pm 5289.0$ & $15226.2 \pm 2761.3$ \\
$\mathrm{AUC}_{(0-\infty)}(\mathrm{h} \mathrm{ng} / \mathrm{mL})$ & $53006.3 \pm 5264.2$ & $15276.2 \pm 2785.4$ \\
$\mathrm{MRT}_{(0-t)}(\mathrm{h})$ & $18.40 \pm 0.64$ & $10.61 \pm 0.63$ \\
$\operatorname{MRT}_{(0-\infty)}(\mathrm{h})$ & $18.39 \pm 0.63$ & $10.61 \pm 0.63$ \\
\hline
\end{tabular}

$(18.39 \pm 0.64 \mathrm{~h})$ allowed it to be detectable in plasma samples after $48 \mathrm{~h}$. Comparatively, methyl eugenol was completely metabolised after 36 hours in view of its short mean residence time $(10.61 \pm 0.63 \mathrm{~h})$.

Previous research found that the pharmacokinetic profiles of the analytes in traditional Chinese medicine (TCM) were slightly different from that observed for their pure forms or other prescriptions [27]. It might due to the complexity of TCM for their interactions among so many compounds in vivo. Therefore, using Asarum extracts to study the pharmacokinetics of safrole and methyl eugenol can provide a more scientific explanation of the pharmacokinetic changes of these two components in vivo. This work can provide the experimental basis for the clinical use of Asarum and its prescriptions. 


\section{Conclusion}

A rapid and sensitive GC-MS method with SIM mode was developed to determine safrole and methyl eugenol in rat plasma after oral administration of the essential oil extracts of Asarum in this study. It has been found that safrole and methyl eugenol both can be absorbed into blood well. Safrole was absorbed at a slower rate in vivo when compared to methyl eugenol. This is the first time that reporting a GCMS method used for the accurate determination and pharmacokinetic analysis of safrole and methyl eugenol in rats plasma after oral administration of the essential oil of Asarum with given concentrations of $20 \mathrm{~g} / \mathrm{kg}$. The pharmacokinetic parameters provided valuable information for the further development and clinical application of Asarum.

\section{Data Availability}

The data used to support the findings of this study are available from the corresponding author upon request.

\section{Conflicts of Interest}

The authors declare no conflict of interests.

\section{Acknowledgments}

This study was supported by the National Natural Science Foundation of China (81673824).

\section{References}

[1] C. P. Committee, Pharmacopoeia of the People's Republic of China, vol. I, Chemical Industry Press, Beijing, 2015.

[2] Y. L. Li, M. Tian, J. Yu, M. Y. Shang, and S. Q. Cai, "Studies on morphology and aristolochic acid analogue constituents of Asarum campaniflorum and a comparison with two official species of Asari radix et rhizoma," Journal of Nature Medicine, vol. 64, no. 4, pp. 442-451, 2010.

[3] T. Iwashina, J. Kitajima, T. Shiuchi, and Y. Itou, "Chalcones and other flavonoids from Asarum sensu lato (Aristolochiaceae)," Biochemical Systematics \& Ecology, vol. 33, no. 6, pp. 571-584, 2005.

[4] J. Han, C. Sun, and M. Ji, "Recent advance of Chinese herbAsarum," Chinese Agricultural Science Bulletin, vol. 27, pp. 46-50, 2011.

[5] Z. Zhang and H. Kang, "Protective effect of Asarum sieboldii essential oil on ovalbumin induced allergic rhinitis in rat," Bioscience reports, vol. 40, no. 6, 2020.

[6] H. H. Yu, S. J. Seo, J. M. Hur, H. S. Lee, Y. E. Lee, and Y. O. You, "Asarum sieboldii extracts attenuate growth, acid production, adhesion, and water-insoluble glucan synthesis of Streptococcus mutans," Journal of Medicinal Food, vol. 9, no. 4, pp. 505-509, 2006.

[7] S. J. Kim, C. Gao Zhang, and J. Taek Lim, "Mechanism of antinociceptive effects of Asarum sieboldii Miq. Radix: potential role of bradykinin, histamine and opioid receptor-mediated pathways," Journal of Ethnopharmacology, vol. 88, no. 1, pp. 5-9, 2003.

[8] A. Haque, J. N. Moon, P. S. Saravana, A. Tilahun, and B. S. Chun, "Composition of _Asarum heterotropoides var. man- dshuricum radix oil from different extraction methods and activities against human body odor-producing bacteria," Journal of Food and Drug Analysis, vol. 24, no. 4, pp. 813-821, 2016.

[9] J. Huang, H. Q. Wang, C. Zhang, G. Y. Li, R. C. Lin, and J. H. Wang, "A new tetrahydrofuran-type lignan with antiinflammatory activity from Asarum heterotropoides Fr. Schmidt var. mandshuricum," Journal of Asian Natural Products Research, vol. 16, no. 4, pp. 387-392, 2014.

[10] Y. Sunohara, Y. Baba, S. Matsuyama, K. Fujimura, and H. Matsumoto, "Screening and identification of phytotoxic volatile compounds in medicinal plants and characterizations of a selected compound, eucarvone," Protoplasma, vol. 252, no. 4, pp. 1047-1059, 2015.

[11] H. Wu, J. Li, F. Zhang, L. Li, Z. Liu, and Z. He, "Essential oil components from Asarum sieboldii Miquel are toxic to the house dust mite Dermatophagoides farinae," Parasitology Research, vol. 111, no. 5, pp. 1895-1899, 2012.

[12] S. H. Liu, W. C. Chuang, W. Lam, Z. Jiang, and Y. C. Cheng, "Safety surveillance of traditional Chinese medicine: current and future," Drug Safety, vol. 38, no. 2, pp. 117-128, 2015.

[13] B. Cai, "Chemical mechanism research during Chinese medicine processing," Planta Medica, vol. 77, no. 12, 2011.

[14] G. Yao, W. Ma, X. Huang et al., "Identification and quality evaluation of raw and processed Asarum species using microscopy, DNA barcoding, and gas chromatography-mass spectrometry," Journal of Analytical Methods in Chemistry, vol. 2020, Article ID 2690238, 12 pages, 2020.

[15] R. Tremmel, K. Herrmann, W. Engst et al., "Methyleugenol DNA adducts in human liver are associated with SULT1A1 copy number variations and expression levels," Archives of Toxicology, vol. 91, no. 10, pp. 3329-3339, 2017.

[16] M. Carlson and R. D. Thompson, "Liquid chromatographic determination of safrole in sassafras-derived herbal products," Journal of AOAC International, vol. 80, no. 5, pp. 1023-1028, 1997.

[17] IARC Working Group on the Evaluation of Carcinogenic Risks to Humans, "IARC Monogr Eval Carcinog Risks Hum 101," 2013, http://monographs.iarc.fr/ENG/Classification/ latest_classif.php.

[18] J. L. Burkey, J. M. Sauer, C. A. McQueen, and I. Glenn Sipes, "Cytotoxicity and genotoxicity of methyleugenol and related congeners - a mechanism of activation for methyleugenol," Mutation Research, vol. 453, no. 1, pp. 25-33, 2000.

[19] A. Schecter, G. W. Lucier, M. L. Cunningham et al., "Human consumption of methyleugenol and its elimination from serum," Environmental Health Perspectives, vol. 112, no. 6, pp. 678-680, 2004.

[20] A. H. Yang, L. Zhang, D. X. Zhi, W. L. Liu, X. Gao, and X. He, "Identification and analysis of the reactive metabolites related to the hepatotoxicity of safrole," Xenobiotica, vol. 48, no. 11, pp. 1164-1172, 2018.

[21] J. R. Kim, H. Perumalsamy, J. H. Lee, Y. J. Ahn, Y. S. Lee, and S. G. Lee, "Acaricidal activity of Asarum heterotropoides rootderived compounds and hydrodistillate constitutes toward Dermanyssus gallinae (Mesostigmata: Dermanyssidae)," Experimental \& Applied Acarology, vol. 68, no. 4, pp. 485495, 2016.

[22] C. Li, F. Xu, C. Cao et al., "Comparative analysis of two species of Asari Radix et Rhizoma by electronic nose, headspace GCMS and chemometrics," Journal of Pharmaceutical and Biomedical Analysis, vol. 85, pp. 231-238, 2013. 
[23] H. Wen, H. Y. Gao, W. Qi et al., "Simultaneous determination of twenty-two components in Asari Radix et Rhizoma by ultra performance liquid chromatography coupled with quadrupole time-of-flight mass spectrometry," Planta Medica, vol. 80, no. 18, pp. 1753-1762, 2014.

[24] I. Papoutsis, A. Rizopoulou, P. Nikolaou, C. Pistos, C. Spiliopoulou, and S. Athanaselis, "A validated GC/MS method for the determination of amisulpride in whole blood," Journal of Chromatography B, vol. 947-948, pp. 111-116, 2014.

[25] A. Orfanidis, O. Mastrogianni, A. Koukou et al., "A GC-MS method for the detection and quantitation of ten major drugs of abuse in human hair samples," Journal of Chromatography B, vol. 1047, pp. 141-150, 2017.

[26] M. Santivañez-Veliz, E. Moreno-Viguri, S. Pérez-Silanes et al., "Development, validation and application of a GC-MS method for the simultaneous detection and quantification of neutral lipid species in Trypanosoma cruzi," Journal of Chromatography B, vol. 1061-1062, pp. 225-232, 2017.

[27] W. Li, B. Hong, Z. Li, Q. Li, and K. Bi, "GC-MS method for determination and pharmacokinetic study of seven volatile constituents in rat plasma after oral administration of the essential oil of_Rhizoma Curcumae_," Journal of Pharmaceutical and Biomedical Analysis, vol. 149, pp. 577-585, 2018. 